\title{
Author/Subjet Indexes Vol. 94, Suppl. 1,1995
}

Bergman, G.E. 43 Berntorp, E. 8 Chandra, S. 25 Deitcher, S.R. 12 Djulbegovic, B. 43

Drummond, O. 18 Feldman, F. 25 Ferguson, J. 18 Gowell,K,P. 12 Hannan, M.M. 43 Huang, C. 25

Limentani, S.A. 12 Ljung,R.C.R. 49 MacGregor, I. 18 McLaughlin, L. 18 Martinowitz, U.P. 35 Prowse, C. 18 Savidge, G.F. 1 Scharrer, I. 2 Schulman, S. 35 White, G.C., II 53

Subject Index Vol. 94, Suppl. 1,1995

$\varepsilon$-Aminocaproic acid 43 Antifíbrinolytic agent 43 Concentrates, highly purified 2, 53

Contaminants 12 Continuous infusion 35 Deletions 49 Exon 49 Factor VIII 35 Factor IX 35,49

- concentrate(s) 25

- -, high-purity 12, 18 Fibrinopeptide A 18 Hemophilia B 12,25,43,49 Hemostasis 43

High-purity factor IX concentrates 12 Immunoaffinity chromatography 25 Inhibitors 49

Missense mutations 49

Monoclonal antibody-purified factor IX 43 Mononine 25, 53 Nonsense mutations 49

Pharmacokinetics 35 Pharmacokinetic variables 8 Prothrombin complex concentrates 2, 8, 18,53 Purified factor IX concentrates 8 Stability 35

Stasis and nonstasis models 18 Thrombogenic properties 8 Thrombogenicity 18,53 Thrombosis 43, 53 Thrombotic complications 2,12 Tranexamic acid 43 Viral contaminants 2 Vitamin Kdependent proteins 12 